\author{
ARNAU PRATS PUNTÍa \\ JUAN PEDRO MARTÍN VIDE \\ CARLES FERRER BOIX
}

\title{
REGRESSIÓ DEL DELTA DEL LLOBREGAT. EFECTE DE LES OBRES D'ENGINYERIA AL RIU D'ENÇÀ DEL SEGLE XIX
}

\begin{abstract}
RESUM
La pressió humana recent envers el Llobregat, un riu al·luvial mediterrani, ha canviat fortament els seus paisatges fluvial i deltaic. La reducció d'aportació de sediment groller del riu va provocar un canvi de tendència en l'evolució del delta a finals del segle xix que ha resultat en una regressió de la línia de costa fins a $800 \mathrm{~m}$. L'article se centra en la component fluvial del sistema riu-delta-mar, tractant de lligar-la amb l'evolució del delta, i s'analitzen els canvis en el transport sòlid de fons provocats per les obres d'enginyeria fetes al riu. Es desenvolupa un mètode per calcular l'evolució del transport sòlid de fons a partir d'informació actual i del passat de la morfologia del riu i del seu règim hidrològic. Els resultats obtinguts demostren que els endegaments fets els darrers setanta anys al curs baix del Llobregat per a permetre el pas d'infraestructures han disminuït la disponibilitat de sediment i modificat la morfologia del riu, però no han estat la causa principal de la reducció de l'aportació de sediment groller cap a la costa. La construcció de nombroses rescloses al curs mig del riu al llarg del segle xix i un canvi en

a Departament d'Enginyeria Civil i Ambiental, Universitat Politècnica de Catalunya. Jordi Girona, 1-3. 08034 Barcelona. arnau.prats@upc.edu. http://orcid.org/0000-0002-9142-6626.

b Departament d'Enginyeria Civil i Ambiental, Universitat Politècnica de Catalunya. Jordi Girona, 1-3. 08034 Barcelona. juan.pedro.martin@upc.edu. http://orcid.org/0000-0002-3914-615X.

c Professor Serra Húnter, Departament d'Enginyeria Gràfica i de Disseny, Universitat Politècnica de Catalunya. Eduard Maristany, 16. 08019 Barcelona. carles.ferrer@upc.edu. http://orcid.org/0000-0002-5605-8979.

Mantenir correspondència amb el primer autor.

L'ordre de firma ha estat escollit d'aquesta manera ja que el primer autor ha estat qui ha escrit el cos del document. El segon autor ha fet la revisió i propostes de millora del text. Els tres autors, en treball amb equip, hem realitzat les tasques de recerca, investigació, càlcul i discussió que han permès fer aquest article.
\end{abstract}

Fecha de recepción: 07-07-2021. Fecha de aceptación: 04-01-2022. 
la freqüència de les crescudes extraordinàries serien responsables del retrocés de la línia de la costa del delta iniciat a tombant de segle. La retenció de sediment als tres embassaments de capçalera és menys important per l'aportació fluvial a la costa que l'efecte de regulació del règim hidrològic (reducció dels cabals alts). Finalment, el desviament del tram final del riu amb la nova desembocadura resultant, inaugurada l'any 2004, ha provocat una reducció d'un ordre de magnitud de l'aportació de sediment del riu a la costa, comprometent així encara més el futur de les platges del delta.

PARAules Clau: transport sòlid; regressió de deltes; impactes a rius; morfodinàmica; rescloses; preses.

\title{
LLOBREGAT DELTA RETREAT. EFFECTS OF THE ENGINEERING WORKS SINCE 19TH CENTURY
}

\begin{abstract}
The recent human pressure upon the Llobregat River, an alluvial bed Mediterranean river, has changed its riverine and deltaic landscapes. The decrease in the coarse sediment yield into the sea has caused a shift in the delta evolution at the end of the $19^{\text {th }}$ century which has resulted in a coastline retreat of $800 \mathrm{~m}$ (a set of data unknown so far). The paper concentrates on the fluvial component of the river-delta-sea system, trying to connect it to the delta evolution, and the possible causes of the delta retreat are analyzed. A method to compute the actual bed load transport with real information of the past river morphology and hydrological regime is developed. The encroachment (and channelization) by road and railway infrastructures built in the low valley in the last 70 years has reduced the sediment supply in the last $30 \mathrm{~km}$ of the river and caused important changes on fluvial morphology, but this is not the main cause of the coarse sediment yield decrease. Moreover, a number of weirs built throughout the 19th century and changes in flood frequency may be responsible for a baseline delta retreat starting at the beginning of the $20^{\text {th }}$ century. The sediment accumulation behind the three dams built in the second half of the $20^{\text {th }}$ century is less important for yearly sediment yield at the lower course than the flow regulation. Finally, the deviation of the final river reach and the resulting new river mouth, built in 2004, has become a sediment trap which poses a further thread to the future of the deltaic beaches since it has caused a decrease in the sediment yield into the sea of one order of magnitude.
\end{abstract}

KEYwORDs: sediment load; delta retreat; river pressures; morphodynamics; weirs; dams.

\section{INTRODUCCIÓ}

Els deltes són protuberàncies de la línia de costa que es formen on un sistema al·luvial entra a un mar (o llac) i subministra sediment de forma més ràpida que la capacitat dels processos marítims per redistribuir-lo (Orton \& Reading, 1993). La importància relativa entre l'aportació de sediment fluvial i el modelatge exercit per l'acció de l'onatge i de la marea en determina la seva morfologia i evolució (Bridge, 2003). En el cas del Mediterrani, on no hi ha marees destacables, el factor marítim rellevant 
és únicament l'onatge, el qual genera un transport longitudinal de sediment al llarg de la costa. Com major és l'aportació de sediment fluvial més sobresurt el delta dins la massa d'aigua, mantenint el factor marítim constant, i viceversa. Per tant, els canvis o impactes en el transport de sediment (també anomenat transport sòlid) d'un riu modifiquen l'aportació fluvial a la costa i són determinants per l'evolució d'un delta. La bibliografia és abundant tant en l'estudi de l'evolució de deltes com de l'evolució de rius, però la connexió entre ambdós actors és menys coneguda en termes físics, tot i les aproximacions estadístiques realitzades (Ibáñez et al., 2019).

Del transport de sediment fluvial, la fracció de sediment groller (sorres i graves), transportada pel fons, és la que contribueix a la progressió de la línia de costa; mentre que el sediment fi (llims o argiles), transportat en suspensió, contribueix a revertir la subsidència quan es diposita a la plana deltaica (Ibáñez et al., 2019). El transport sòlid de fons és el resultant del balanç entre el subministrament de sediment provinent d'aigua amunt i la capacitat de transport sòlid del tram (Einstein, 1964). Les actuacions antròpiques realitzades a un riu i la seva conca (e.g., construcció de preses, extraccions d'àrids, endegaments, reforestació) poden reduir de forma brusca i important el subministrament i/o la capacitat de transport sòlid, i provocar la regressió d'un delta degut a la disminució de l'aportació fluvial (Syvitski \& Saito, 2007).

A la regió mediterrània, la regressió de les platges especialment en deltes és una gran preocupació (Sánchez-Arcilla et al., 2008). Al Nord-est de la península Ibèrica, concretament a la costa central catalana, hi trobem el delta del Llobregat. S'ha format gràcies a l'aportació de sediment feta pel riu Llobregat, que en llatí s'anomenava Rubricatus, que significa enrogit, en al·lusió al color de les seves aigües probablement degut al seu elevat transport de sediment fi. De l'evolució històrica del delta se'n coneix que la línia de costa ha progressat més de $3 \mathrm{~km}$ cap al mar des de l'època dels romans en algunes zones (Marquès, 1984), resultant en un augment de superfície molt important. En canvi, durant el segle xx l'evolució del delta ha esdevingut una dinàmica regressiva tal i com demostren les dades d'un retrocés superior a $300 \mathrm{~m}$ a les platges més properes a la desembocadura entre els anys 1949 i 1990 (Marcos, 1995). Aquesta regressió de la costa més popera a la desembocadura només pot haver estat possible per una reducció important de l'aportació fluvial, provocada possiblement per les diferents obres d'enginyeria que s'han realitzat en tot el curs del Llobregat des de mitjans del segle xix i sobretot a partir del segle xx. Els estudis fets fins el moment no permeten establir quines han estat les causes de la disminució de l'aportació de sediment del Llobregat a la costa que ha provocat la regressió del delta, ni tampoc quan es va iniciar exactament aquesta regressió.

L'objectiu d'aquest estudi és relacionar la disminució de l'aportació de sediment groller del riu Llobregat a la costa amb la regressió del seu delta. Per fer-ho ha calgut estimar l'evolució de la costa del delta, l'evolució del transport sòlid de fons del riu al curs baix, i analitzar una per una les causes de la reducció d'aportació de sediment, fent especial èmfasi en l'impacte de les següents obres d'enginyeria: embassaments, rescloses, i endegaments. Els resultats obtinguts són útils per determinar quines mesures són més eficaces per recuperar el subministrament natural de sorra a les platges del delta i millorar la gestió del riu Llobregat i la seva conca. 


\section{Àmbit D'Estudi}

El Llobregat és un riu de $163 \mathrm{~km}$ de longitud que drena una conca de $4.925 \mathrm{~km}^{2}$ del Nord-est de la península Ibèrica, amb la capçalera situada al sector oriental dels Pirineus, i que desemboca al mar Mediterrani formant un delta (figura 1). El delta actual té una superfície aproximada de $100 \mathrm{~km}^{2}$ i està limitat al Nord per la muntanya de Montjuïc i el port de Barcelona, i a l'Oest pel massís del Garraf. Entre aquests dos límits la costa original era una successió de platges contínues que sumaven $24 \mathrm{~km}$ de longitud, però l'ampliació progressiva del port de Barcelona fins a ocupar tot l'hemidelta Nord i la construcció de port Ginesta el 1986 a l'hemidelta Sud, ha provocat la pèrdua de més de 6 km de platja. A uns centenars de metres de la riba esquerra del riu s'alça el far del Llobregat, un edifici històric construït l'any 1567 que és un punt de control excel·lent de l'evolució de la línia de costa a prop de la desembocadura (figura 2a i 2b). La mida mitjana de la sorra de les platges és de $280 \mu \mathrm{m}$ (Gràcia \& Calafat, 2019), i el transport longitudinal d'aquesta sorra al llarg de la costa per l'acció de l'onatge té un sentit predominant de NE a SW, amb una capacitat de transport en un rang comprès entre $10 \times 10^{3}-75 \times 10^{3} \mathrm{~m}^{3} /$ any (CIIRC, 2010). Originalment, abans de la construcció de port Ginesta, el delta no era una cel·la sedimentària tancada ja que el límit Oest era parcialment obert pel transport longitudinal de sediment (Gràcia \& Calafat, 2019).

Pel que fa al riu, el seu curs baix comprèn els darrers $30 \mathrm{~km}$ des de la confluència amb l'Anoia, just aigua amunt del pont del Diable de Martorell (figura 1b), fins a la desembocadura al delta. Aquest és l'àmbit del riu que s'ha analitzat amb més detall en aquest estudi, i per un anàlisi més acurat de l'evolució temporal del transport sòlid s'ha dividit en cinc trams, de l'1 al 5 en sentit descendent (figura 1b). A la vall, en els tres primers trams (1-3), el Llobregat és un riu amb llit de graves que en el seu estat pristí tenia una morfologia divagant amb una llera ampla, lleugerament trenada i amb possibilitat de mobilitat en planta dins l'extensa plana al-luvial d'ambdós costats del riu. En els dos darrers trams (45) el riu té un llit al-luvial de sorres i flueix per la plana deltaica amb una morfologia meandriforme, caracteritzada per una sola llera sinuosa, amb unes vores més estables i un pendent més suau. Aquesta transició abrupta del material al·luvial del llit de graves a sorres normalment succeeix juntament amb un canvi sobtat del pendent longitudinal i de la morfologia (Cui \& Parker, 1998), tal com és el cas del Llobregat. Una conseqüència important d'aquesta transició és que el tram 5 , que subministra sediment a la línia de la costa, té una mida de les partícules del llit de $\mathrm{D}_{50}=600 \mu \mathrm{m}$, similar a la mida de la sorra de les platges del delta. Al límit entre els trams 3 i 4 hi ha una estació d'aforament que mesura el cabal d'aigua del riu. 


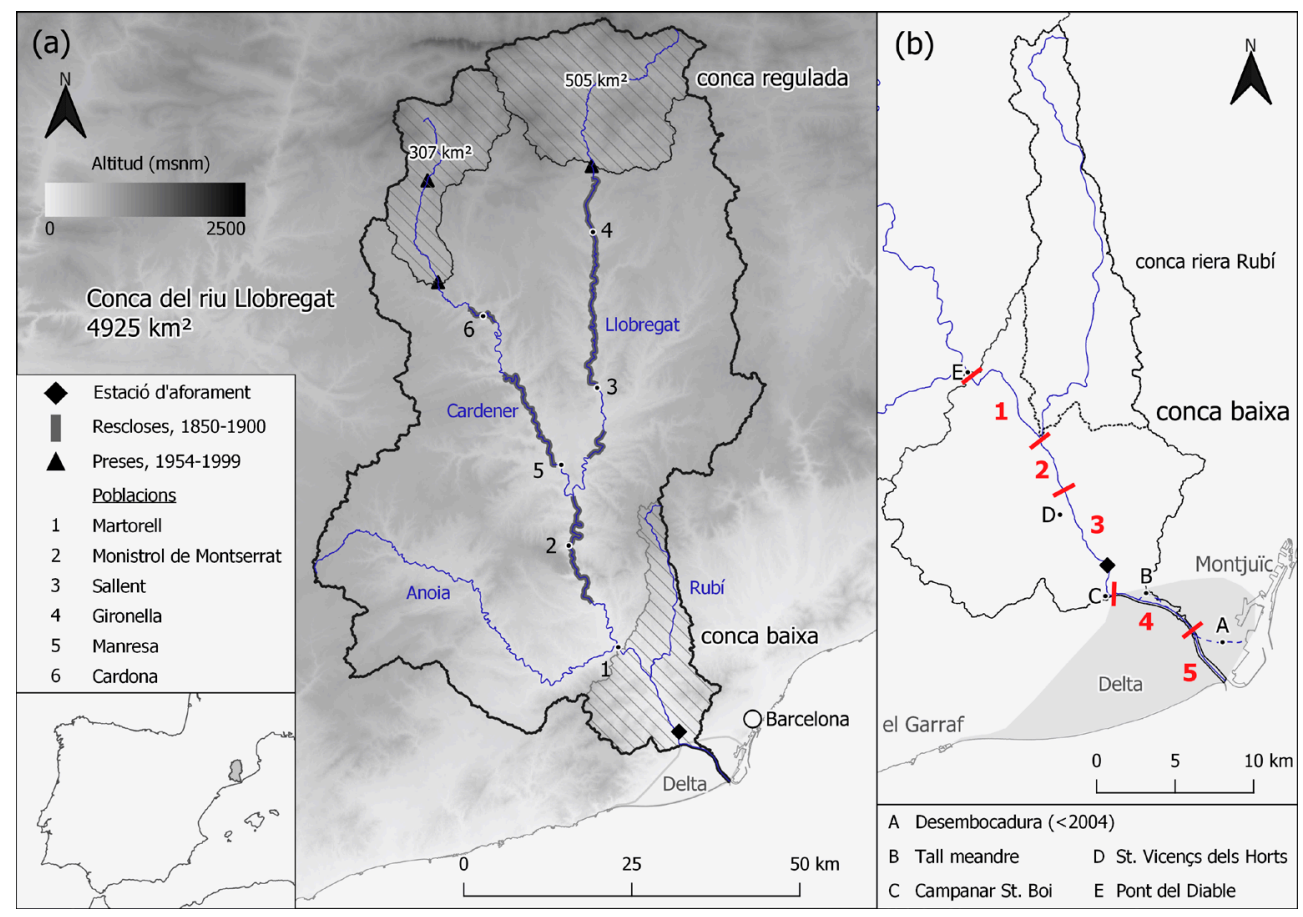

Figura 1. (a) Mapa d'emplaçament de la conca del Llobregat. (b) Ampliació de la part baixa de la conca amb la divisió del curs baix en 5 trams pel seu anàlisi i on es mostra la localització de l'estació d'aforament i dels topònims que es mencionen al llarg de l'article.

Actualment a la capçalera de la conca del Llobregat hi ha dues àrees regulades per embassaments (figura 1a). Una presa construïda l'any 1975, la Baells, regula una superfície de $505 \mathrm{~km}^{2}$ amb un embassament de $109 \mathrm{hm}^{3}$. La segona presa, Sant Ponç, construïda l'any 1954 al curs mig del Cardener, el principal afluent del Llobregat, regula una superfície de $307 \mathrm{~km}^{2}$ amb un embassament de $24 \mathrm{hm}^{3}$ de capacitat (a l'interior d'aquesta àrea regulada l'any 1999 es va construir la presa de la Llosa del Cavall). La superfície total regulada hidrològicament pels embassaments (la conca regulada) és de $812 \mathrm{~km}^{2} \mathrm{i}$ representa un 16,5\% de la conca del Llobregat. Cap de les tres preses disposa de sistemes per permetin el pas del sediment acumulat.

Durant el període temporal d'aquest estudi, des de la segona meitat del segle xix fins a l'actualitat, s'han realitzat diverses obres d'enginyeria a la llera del Llobregat i a la seva conca que poden haver provocat impactes en el transport de sediment del riu; aquestes obres són: construcció de multitud de rescloses (també anomenades assuts) especialment al curs mig del riu per aprofitar l'energia hidràulica durant l'arribada de la Revolució Industrial a Catalunya, convertint el Llobregat en "el riu més treballador"; regulació del curs alt mitjançant la construcció de grans preses; estrenyiment de la llera i ocupació de la plana d'inundació de molts cursos fluvials de la conca degut a la construcció d'infraestructures i 
endegaments, destacant especialment les obres realitzades al curs baix del riu des de la segona meitat del segle xx; desviació de la desembocadura del riu tres km al Sud l'any 2004 per l'ampliació del port de Barcelona creant una llera d'amplada més del doble que l'original i propensa a l'acumulació de sediment. A més d'aquestes obres, els canvis d'usos del sòl produïts a la conca i les extraccions de material al·luvial de la llera (es té constància que se n'han fet però no es disposa de dades) també poden haver provocat impactes en el transport de sediment.

\section{Materials I MÈTODes}

\section{Cartografia històrica}

Les fonts cartogràfiques utilitzades per tal d'analitzar tant l'evolució de la costa del delta del Llobregat com la del riu, han consistit en plànols i mapes històrics disponibles als arxius públics i imatges aèries georeferenciades. Les fonts cartogràfiques obtingudes dels arxius històrics són els primers mapes i plànols fets a escala i de forma precisa, fet que permet obtenir informació molt valuosa del període comprès entre mitjans del segle xix i mitjans del segle xx, abans de la realització de les primeres imatges aèries. De l'Arxiu Històric de la Ciutat de Barcelona s'han obtingut plànols de la costa del delta que daten del 1859, 1882, 1891, 1902, 1909 i 1926. De l'Arxiu Nacional de Catalunya (ANC) s'han obtingut dos plànols dels anys 1846 i 1854 que representen la llera i plana d'inundació del Llobregat en els trams 3 i 4 de l'àmbit d'estudi del riu. Mitjançant tècniques SIG ha estat possible georeferenciar els plànols de la costa del 1891 i 1926, i els del riu del 1846 i 1854. L'anàlisi de l'evolució del delta i del riu des de mitjans del segle xx fins a l'actualitat s'ha fet a partir d'imatges aèries georeferenciades. De l'Institut Cartogràfic i Geològic de Catalunya (ICGC) s'han utilitzat les imatges obtingudes pels vols dels anys 1946, 1956, 2000 i 2016; i del departament de cartografia de l'Àrea Metropolitana de Barcelona (AMB) les imatges dels anys 1965, 1974 i 1981. Del Centre de Recerca Ecològica i Aplicacions Forestals (CREAF) s'han obtingut els mapes de cobertes del sòl dels anys 1956 i 2009. Mitjançant aquests mapes s'han obtingut els resultats dels canvis d'usos del sòl a la conca del Llobregat.

\section{Evolució de la costa}

Gràcies a que apareix en tots els plànols històrics de la costa consultats, el far del Llobregat s'ha utilitzat com a punt de control de l'evolució de la costa del delta a la desembocadura. Mesurant la distància entre el far i la costa ha estat possible determinar l'evolució de la costa en aquest punt des del 1859, data del primer plànol a escala on apareix, fins el 1956, darrera data abans que s'hagués de protegir el far amb escullera degut al retrocés de la costa.

Per l'anàlisi de l'evolució del delta s'ha traçat la posició de la línia de costa (de platja) corresponen als anys 1891, 1926 (només hemidelta Nord), 1946, 1956, 1965, 1974, 1981 i 2000 (només hemidelta Sud), utilitzant el software QGIS 3.4 $4^{\circ}$. A partir d'aquestes línies, utilitzant el programa Digital Shoreline Analysis System (DSAS) de l'U.S.G.S. s'han calculat els valors d'avenç/retrocés de la costa, els volums de sorra guanyats/perduts i les respectives taxes d'evolució anual. L'anàlisi de l'avenç/ 
retrocés de la costa s'ha limitat al període 1891-1981, i el càlcul de la variació de volum de sorra de les platges a 1946-1981, degut a les següents intervencions modernes que han modificat la costa: ampliació del port de Barcelona (la figura 2a mostra que l'any 2000 el port s'estenia fins a la riba esquerra del riu), construcció de port Ginesta el 1986, i alimentació artificial de les platges amb sorra mitjançant dragats. Pel càlcul dels volums de sorra s'han utilitzat els valors de profunditat de tancament de la plataforma de platja i d'alçada de la berma de les platges del delta, 6,35 m i entre 0,9 i 1,4 m respectivament (CIIRC, 2010). S'ha considerat un valor de $35 \%$ de porositat per tal de fer el pas de volums bruts a volums nets de sorra.

\section{Règim hidrològic amb i sense embassaments}

Les dades de l'estació d'aforament de Sant Joan Despí (figura 1), en funcionament des de l'any 2002, s'han utilitzat per elaborar una corba de cabals classificats ${ }^{1}$ del curs baix del Llobregat pel període 2002-2018. Aquest període, posterior a la construcció de l'última gran presa de la conca l'any 1999, és prou llarg per representar una corba de cabals classificats característica del règim hidrològic actual del Llobregat, regulat pels tres embassaments de capçalera. De fet, el període és suficient per representar correctament els cabals normals i les crescudes anuals però no per tenir en compte les grans crescudes, aquelles que tenen un període de retorn superior als 10 anys. La corba de cabals classificats s'ha obtingut a partir de les dades de cabal horàries de l'estació d'aforament, ordenant-les totes de major a menor cabal, i realitzant les mitjanes corresponents per tal d'obtenir un valor pels 365 dies de l'any.

Una contribució d'aquest estudi és que mitjançant la mateixa sèrie de dades de l'estació d'aforament, juntament amb els nivells diaris reals dels tres embassaments de la conca pel mateix període, s'obté una corba de cabals classificats del Llobregat sense embassaments, que és una corba hipotètica que representa el règim hidrològic natural, previ a l'any 1954. Aquest procés es realitza afegint o sostraient la variació de volum diari (en unitats $\mathrm{de}^{3} / \mathrm{s}$ ) dels embassaments a les dades de cabal horàries mesurades a l'estació d'aforament. Els temps de viatge de l'aigua des de la sortida dels embassaments fins a l'estació (22 hores pel Llobregat i 20 hores pel Cardener) són els temps de demora entre la variació de volum als embassaments i el cabal que s'ha de modificar per suma o resta a l'estació. Per tal que coincideixi l'interval temporal de les dues sèries de dades i poder fer aquest pas, ha calgut transformar les dades diàries dels embassaments a horàries, de tal manera que un valor de variació de volum diari es converteix en 24 valors iguals de variació de volum horari. Un cop fets aquests passos, el procés realitzat per obtenir la corba de cabals classificats sense embassaments és el mateix que per la corba amb embassaments.

1 Corba decreixent que ordena els cabals d'un riu al llarg de l'any de més grans a més petits amb un valor per cada dia. El cabal del dia 1 correspon al valor que de mitjana només es produeix 1 cop l'any, i el del dia 365 al que de mitjana es supera tots els dies de l'any. 


\section{Rescloses}

Tot i que l'impacte de les rescloses en el transport sòlid d'un riu és important i pot provocar canvis en la morfologia fluvial, és un aspecte menys estudiat que el de les grans preses (Ibisate et al., 2013; Peeters et al., 2020). Els efectes en el transport de sediment de la presència de rescloses en un riu són (i) la retenció de sediment groller i, (ii) la disminució de la capacitat de transport sòlid. El punt de partida per a realitzar una estimació de l'impacte de les rescloses han estat les dades d'alçada i any de construcció de les existents en tot el curs del Llobregat i el Cardener (Alayo, 2017). Mitjançant aquesta informació i un cop geolocalitzades totes les rescloses, a partir del model d'elevacions del terreny de $15 \times 15 \mathrm{~m}$ de l'ICGC s'ha realitzat un perfil longitudinal de l'eix del Llobregat i el Cardener on se'n mostra la seva ubicació i també, per diferents trams del riu, l'evolució de la relació de la suma de l'alçada de les rescloses respecte el desnivell del riu des de l'any 1800 fins al 1950. Mitjançant aquesta relació s'obté el desnivell lliure de rescloses, amb el qual es calcula el pendent longitudinal del riu. Els resultats del pendent longitudinal del riu lliure de rescloses s'han utilitzat com a mesura indirecta de l'evolució de la capacitat de transport sòlid de fons.

\section{Transport sòlid de fons del riu}

$\mathrm{Ni}$ al curs baix del Llobregat ni en tota la seva conca existeix o ha existit mai cap estació de mesura del transport sòlid de fons. Per tant, el transport de fons real del Llobregat no es coneix i s'ha hagut d'estimar mitjançant la utilització d'expressions empíriques de la capacitat de transport, les quals cal ressaltar que proporcionen resultats que poden diferir força respecte el transport real. Pel que fa al transport en suspensió, mitjançant les mesures de terbolesa fetes a l'estació d'aforament del curs baix (figura 1b) entre 1995 i 2002, i assumint una densitat del sediment de 1,1 t/ $/ \mathrm{m}^{3}$, Liquete et al. (2009) han obtingut un valor de $\approx 90 \times 10^{3} \mathrm{~m}^{3} /$ any.

L'àmbit en què s'ha calculat l'evolució del transport de sediment de fons del Llobregat són els 5 trams del curs baix del riu (figura 1b), i el període temporal correspon als anys 1946-1956-1965-19741981-2016. Per a cadascun dels 5 trams, per tant, s'han calculat 6 valors de transport de sediment. Les imatges aèries proporcionen informació de la morfologia en planta de la llera necessària per realitzar els càlculs i és per això que els anys analitzats corresponen a les dates de les imatges aèries. Per aquest motiu, i tot i que es disposa d'informació cartogràfica prèvia d'alguns trams del riu, l'estudi de l'evolució temporal s'inicia l'any 1946.

Per a conèixer el transport sòlid de cada tram i cada data ha calgut estimar el subministrament i la capacitat de transport. L'evolució del subministrament s'ha estimat de forma indirecta a partir de la superfície al·luvial de la llera, ja que la llera proporciona la càrrega de fons (Prats-Puntí, 2018). A més, també s'han utilitzat els plànols de l'ANC dels anys 1846 i 1854, juntament amb la comparació de fotografies històriques i actuals de la llera. Per a la capacitat de transport sòlid de fons també s'han utilitzat els resultats del treball fet per Prats-Puntí (2018), obtinguts aplicant l'expressió de Meyer-Peter i Müller corregida per Wong \& Parker (2006). Per poder aplicar-la a cada tram i data es defineixen, utilitzant les imatges aèries i la documentació d'arxius històrics, els següents aspectes: la dimensió 
mitjana de les partícules del llit al-luvial, el pendent longitudinal de l'eix del riu, una secció transversal característica, i l'amplada al·luvial de la llera. L'expressió s'aplica per tots els cabals de les corbes de cabals classificats amb i sense embassaments. D'aquesta manera és possible quantificar l'impacte que té la regulació del règim hidrològic en la capacitat de transport sòlid del curs baix del Llobregat.

Per últim, s'ha utilitzat el càlcul del volums erosionat a la llera després de la crescuda extraordinària de l'any 2000 obtingut per la comparació de perfils longitudinals (Martín-Vide et al., 2020), i la dada de transport en suspensió del Llobregat (Liquete et al., 2009), per tal de comparar la magnitud del transport sòlid de les grans crescudes respecte al corresponent a un any mitjà i per a validar els valors estimats de capacitat de transport sòlid de fons.

\section{Propagació riu avall dels impactes en el transport de fons}

Els efectes dels impactes en el subministrament del sediment groller (material de transport de fons), tant siguin per disminució o augment de la seva disponibilitat, no es limiten a la zona del riu més propera on s'han produït sinó que es propaguen riu avall com una pertorbació. La pertorbació es dissipa lentament, fruit de la modificació del perfil longitudinal del riu, però els efectes poden afectar tot el curs fins a la desembocadura. La velocitat de propagació de la pertorbació està relacionada amb la velocitat a la que es desplacen les partícules del llit, que és alguns ordres de magnitud inferior a la velocitat del flux l'aigua. Com a conseqüència d'aquesta baixa velocitat, la propagació riu avall és lenta i els efectes es poden acabar manifestant anys després de l'inici de l'impacte. L'estudi de Liébault et al. (2005) va determinar una velocitat de propagació riu avall de 300-500 m/any per l'ona de pertorbació causada per la reforestació d'una conca. En el present estudi, aquesta velocitat s'utilitza per estimar el temps necessari per l'arribada al curs baix del Llobregat i a la seva desembocadura dels impactes en el subministrament produïts pels embassaments de la capçalera, les rescloses i les obres d'enginyeria fetes al curs baix.

\section{Resultats}

\section{Evolució de la costa del delta}

A diferència del creixement general de tot el delta del Llobregat en el passat (Marcos, 1995; Marquès, 1984), la línia de costa ha estat retrocedint de forma important en algunes zones des del començament del segle xx. La figura 2a mostra el retrocés de les platges adjacents a la desembocadura del riu des de l'any 1891 fins el 2000. La regressió màxima és de pràcticament $800 \mathrm{~m}$ en tot el període.

Els resultats obtinguts de la distància entre el Far del Llobregat i la costa demostren que la platja en aquest punt avançava durant la segona meitat del segle xix, assolint l'any 1891 una distància màxima de $355 \mathrm{~m}$ (taula 1). Des de la darrera dècada del segle xix però, es va produir un canvi de tendència i la costa va començar a retrocedir inexorablement de tal manera que a mitjans del segle xx la platja enfront del far havia desaparegut completament (figura 2a). L'anàlisi dels resultats de la taula 1 mostra, a més a més d'aquest canvi de tendència desconegut fins ara, que la taxa mitjana anual de l'evolució de la costa disminueix amb el temps: en el període que la platja augmenta d'amplada (1859-1891) la 
taxa anual d'avenç disminueix ( $\mathrm{de}+2,6 \mathrm{a}+1,1 \mathrm{~m} / \mathrm{any})$, i en el que la platja retrocedeix (1891-1956) la taxa de regressió augmenta (de -3,5 a -8,4 m/any). El valor de -0,7 m/any del període 1902-1909 que trenca aquest ritme podria ser degut a que l'any 1907 es va produir una gran crescuda del riu que va inundar la totalitat del delta (Codina, 1971). El port de Barcelona no hauria d'haver tingut un paper important en la forta regressió de la platja a la desembocadura en aquest període, ja que entre els anys 1859 i 1956 el port estava situat a una distància superior a 3 km, i perquè els plànols mostren que el seu creixement des d'inicis del segle xx (del 1859 fins a 1902 no té cap ampliació) encara es produïa enfront de la muntanya de Montjuïc i no a la costa del delta.

\section{Taula 1. Evolució de la distància entre el Far del Llobregat i la línia de costa i de la taxa anual d'avenç (+) o regressió (-) de la platja respecte la data anterior. Les fonts cartogràfiques utilitzades per obtenir aquestes dades són mapes de l'Arxiu Històric de la Ciutat de Barcelona (1) i imatges aèries geo-referenciades de l'ICGC (2).}

\begin{tabular}{|c|c|c|c|c|c|c|c|}
\hline Any & $\begin{array}{c}\text { Font } \\
\text { cartogràfica }\end{array}$ & $\begin{array}{c}\text { Dist. Far- } \\
\text { costa (m) }\end{array}$ & $\begin{array}{c}\text { Evolució } \\
\text { costa (m/any) }\end{array}$ & Any & $\begin{array}{c}\text { Font } \\
\text { cartogràfica }\end{array}$ & $\begin{array}{c}\text { Dist. Far- } \\
\text { costa (m) }\end{array}$ & $\begin{array}{c}\text { Evolució } \\
\text { costa } \\
\text { (m/any) }\end{array}$ \\
\hline 1859 & 1 & 285 & & 1909 & 1 & 311 & $-0,7$ \\
\hline 1882 & 1 & 345 & $+2,6$ & 1926 & 1 & 237 & $-4,4$ \\
\hline 1891 & 1 & 355 & $+1,1$ & 1946 & 2 & 84 & $-7,7$ \\
\hline 1902 & 1 & 316 & $-3,5$ & 1956 & 2 & 0 & $-8,4$ \\
\hline
\end{tabular}

L'evolució de la costa en tot l'àmbit del delta, ja sigui progressió cap al mar (avenç) o retrocés terra endins (regressió), expressat en metres, es resumeix al gràfic de la figura 2c. L'evolució total al llarg del període 1891-1981 es mostra gràficament respecte una abscissa $x$ que va d'Oest (esquerra) a Nord (dreta), juntament amb l'evolució en dos subperíodes de 55 (1891-1946) i 35 anys (1946-1981) que mostren tendències temporals i oscil-lacions. Al tram entre les abscisses $x=18 \mathrm{~km} \mathrm{i} x=24 \mathrm{~km}$ s'hi observa un contorn oval que sobresurt lleugerament cap al mar, en el qual a la posició $x=21 \mathrm{~km}$ hi ha la desembocadura del riu. En aquest tram de $6 \mathrm{~km}$ la costa ha estat retrocedint d'una manera coherent, en el sentit que a major proximitat respecte la desembocadura major ha estat el retrocés, suggerint això el paper clau d'una reducció de l'aportació de sediment fluvial en l'evolució de la costa. Aquesta tendència és força comuna també pels dos subperíodes. Les platges situades entre $x=0 \mathrm{~km}$ i $x=18 \mathrm{~km}$, en canvi, en general han progressat, si bé en aquesta zona les fluctuacions temporals i espacials han estat més notòries. En aquest tram destaca pel subperíode 1891-1946 l'avenç important de la costa (entre 100 i $200 \mathrm{~m}$ de mitjana), que concorda amb la dada de progressió de la platja de $179 \mathrm{~m}$, entre els anys 1844 i 1934 , mesurada a la caserna situada a $x \approx 17,5 \mathrm{~km}$ (veure figura 2b) per l'estudi de Paladella i Faura (1935). El transport per part de l'acció de l'onatge de la sorra erosionada de les platges adjacents a la desembocadura (regressió mitjana de 300 m entre 1891-1946) cap a l'Oest explicaria l'augment d'amplada d'aquestes platges. 


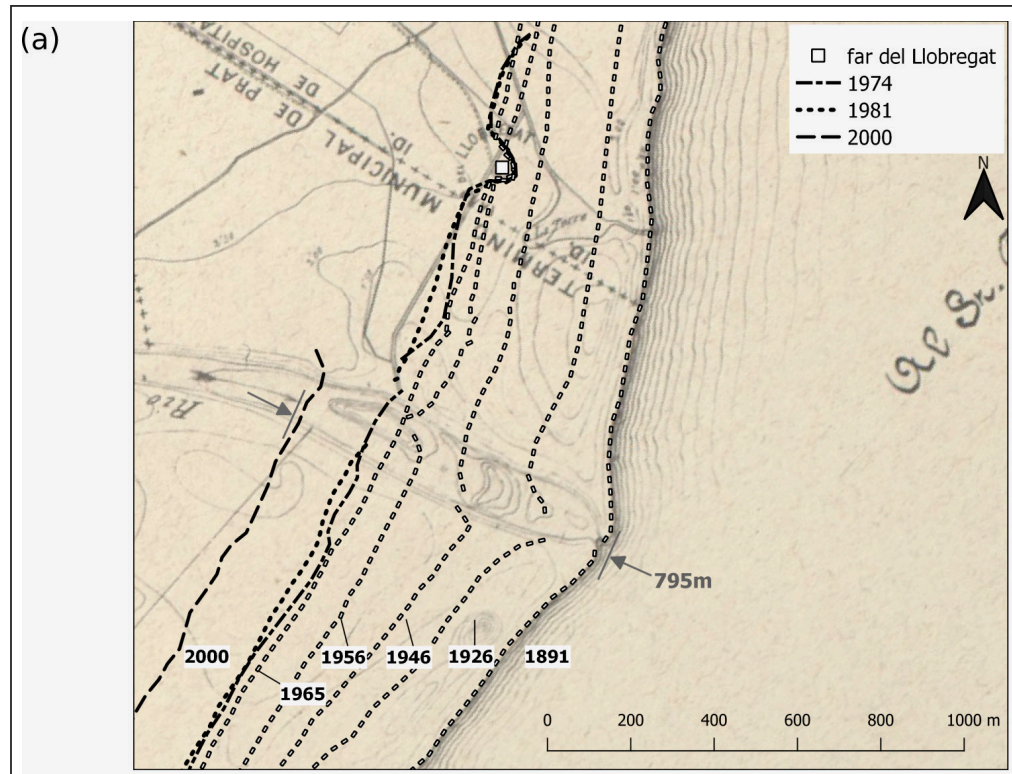

(b)

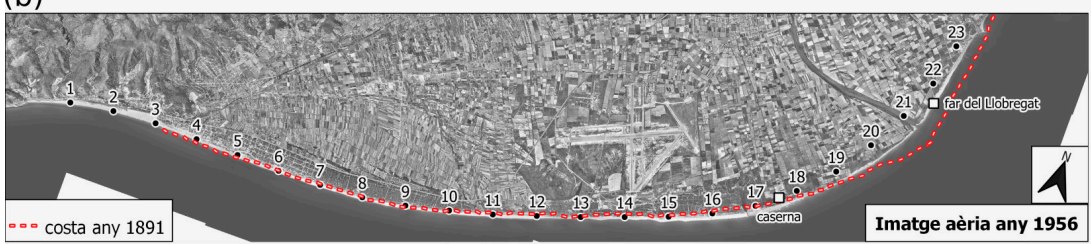

(c)

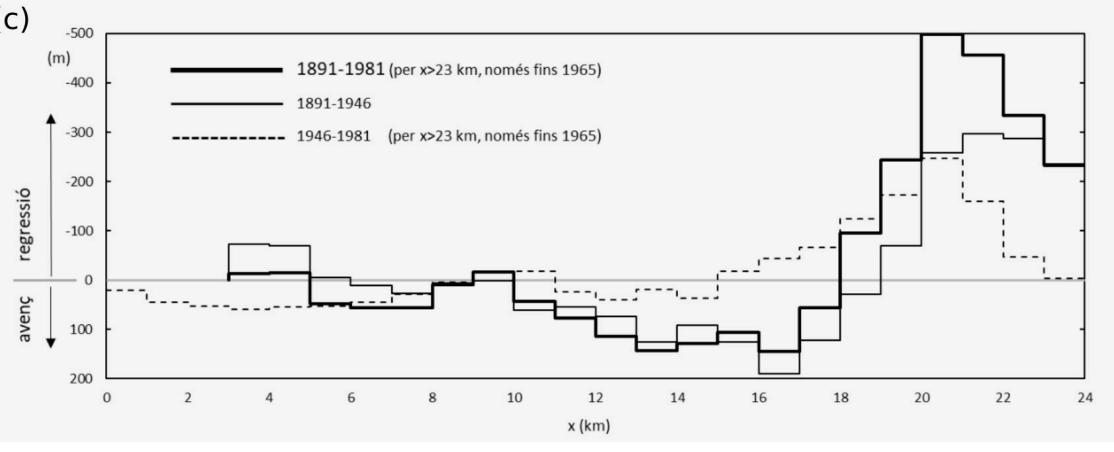

Figura 2. (a) Regressió de la costa del delta del Llobregat a la desembocadura del riu des de l'any 1891 (data del mapa de fons, també) fins a l'any 2000 (el 2004 es desvia el riu al Sud i l'ampliació del port de Barcelona ocupa tota aquesta zona). Figura dels autors feta geo-referenciant les línies de costa dels anys 1891 i 1926 (mapes de l'Arxiu Històric de la Ciutat de Barcelona) i utilitzant imatges aèries de l'ICGC. (b) Imatge aèria dels $24 \mathrm{~km}$ de línia de costa del delta. Es mostra la ubicació del Far del Llobregat i la caserna. (c) Gràfic de la mitjana de l'avenç (+) o retrocés (-) de la costa en tot l'àmbit del delta en trams d'1 km de longitud, pel període 1891-1981 i en dos intervals inclosos. 
Els resultats obtinguts del balanç del volum de sorra de les platges afloren un dèficit de $63 \times 10^{3} \mathrm{~m}^{3} /$ any al Nord $(x=15-24 \mathrm{~km})$ i un augment de $25 \times 10^{3} \mathrm{~m}^{3} /$ any a les platges de l'Oest $(x=0-15 \mathrm{~km})$ pel període 1946-1981. En tres dels quatre períodes el dèficit de sorra de les platges del delta és superior a l'excedent. El balanç negatiu (pèrdua de sorra) es pot explicar pel límit occidental parcialment obert (a $x=0 \mathrm{~km}$ ). La capacitat de transport longitudinal de sediment de la costa (volum net de $10-75 \times 10^{3} \mathrm{~m}^{3} /$ any) sembla capaç, per ordre de magnitud, de transportar aquestes quantitats de sorra des les platges del Nord cap a les de l'Oest i fins i tot de traspassar part d'aquesta sorra a través del límit occidental del delta.

Taula 2. Canvis de volum de sorra $\left(\times 10^{3} \mathrm{~m}^{3}\right.$ /any) de la costa del delta del Llobregat desglossats per dècada i zona (les platges més occidentals i la zona més pròxima a la desembocadura).

\begin{tabular}{|l|c|c|c|c|c|}
\hline Volum net $\left(10^{3} \times \mathrm{m}^{3} / \mathrm{any}\right)$ & $1946-56$ & $1956-65$ & $1965-74$ & $1974-81$ & $1946-81$ \\
\hline Excedent, $x=0-15 \mathrm{~km}$ & $-5^{\mathrm{a}}$ & +32 & $+21^{\mathrm{b}}$ & $+32^{\mathrm{b}}$ & +25 \\
\hline Dèficit, $x=15-24 \mathrm{~km}$ & -84 & -54 & $-52^{\mathrm{c}}$ & $-30^{\mathrm{c}}$ & -63 \\
\hline Balanç (excedent vs. dèficit) & -89 & -22 & -31 & +2 & -38 \\
\hline
\end{tabular}

${ }^{\mathrm{a}}$ És un dèficit, no excedent; noteu el signe menys. ${ }^{\mathrm{b}} \mathrm{Al}$ llarg de $x=5-15 \mathrm{~km} .{ }^{\mathrm{c}} \mathrm{Al}$ Ilarg de $x=15-22 \mathrm{~km}$.

Efectes dels canvis a la llera i la conca en el transport de sediment del riu

Usos del sòl i urbanització

Els canvis d'usos del sòl tenen la capacitat de modificar el transport sòlid d'un riu ja que poden provocar variacions del seu cabal, fruit de l'escolament superficial de la precipitació, i del subministrament de sediment a la llera (sobretot sediment fi). Els resultats de la conca del Llobregat entre 1956 i 2009 es resumeixen a la taula 3, desglossats en tres categories generals. Els percentatges pel conjunt de la conca mostren un canvi modest consistent en la pèrdua de sòl agrícola degut a l'expansió dels nuclis urbans per una banda, i pel creixement forestal (boscos i matollars) en conreus abandonats, per l'altra.

Taula 3. Evolució (percentual) dels usos del sòl en el conjunt de la conca del Llobregat, la conca baixa i la conca de la riera de Rubí, entre els anys 1956 i 2009. Font: (Prats-Puntí, 2018)

\begin{tabular}{|l|c|c|c|c|c|c|}
\cline { 2 - 7 } \multicolumn{1}{c|}{} & \multicolumn{2}{c|}{ Conca, $4.925 \mathrm{~km}^{2}$} & \multicolumn{2}{c|}{ Conca baixa, $343 \mathrm{~km}^{2}$} & \multicolumn{2}{c|}{ Conca Rubí, $124 \mathrm{~km}^{2}$} \\
\cline { 2 - 7 } \multicolumn{1}{c|}{} & 1956 & 2009 & 1956 & 2009 & 1956 & 2009 \\
\hline Agrícola & $35 \%$ & $22 \%$ & $43 \%$ & $8 \%$ & $45 \%$ & $9 \%$ \\
\hline Zona urbana & $2 \%$ & $8 \%$ & $6 \%$ & $37 \%$ & $8 \%$ & $43 \%$ \\
\hline Forestal & $63 \%$ & $70 \%$ & $51 \%$ & $55 \%$ & $47 \%$ & $48 \%$ \\
\hline
\end{tabular}

Per la conca baixa del Llobregat, que representa un 7\% del total de la conca (figura 1a), la pèrdua de terreny agrícola és de major importància i beneficia més la zona urbana que la forestal. El curs baix 
del Llobregat, pròxim a Barcelona, és el tram més intervingut i amb més canvis. El cas de la conca més urbanitzada, la de la riera de Rubí, mostra una transformació més forta d'usos del sòl entre els terrenys agrícoles i les àrees urbanes (taula 3, localització a la figura 1b). Aquest afluent té molts trams endegats però no hi ha cap presa. Per tant, les obres fetes a la llera i l'augment d'escolament superficial degut a la forta urbanització han d'haver estat les causes dominants en la important incisió de la llera detectada en aquest riera des de l'any 1962 (Martín-Vide \& Andreatta, 2009).

\section{Embassaments: retenció de sediment}

La fracció del transport sòlid provinent de la conca regulada transportada en suspensió, la càrrega de rentat, es quedarà majoritàriament atrapada als embassaments, però aquesta component del transport que té una mida de les partícules corresponent al rang de l'argila i el llim (fins a $62 \mu \mathrm{m}$ ) no és rellevant per l'evolució de la línia de la costa, composta de sorra fina $(280 \mu \mathrm{m})$. Pel que fa a la fracció grollera -provinent del material al-luvial de les lleres, que acaba tota retinguda als embassaments i que sí que és rellevant per la costa-i la densitat de la xarxa de drenatge són similars pel conjunt de la conca però la pluviometria i el pendent dels cursos fluvials és major a la conca regulada. Conseqüentment, el subministrament de sediment groller provinent de les lleres retingut als embassaments és probablement superior al valor del percentatge de conca regulada $(16,5 \%)$ ja que la major part de l'erosió natural té lloc a les zones muntanyoses (Wilkinson \& McElroy, 2007).

La interrupció total del transport de sediment groller per part de les preses provoca un dèficit de subministrament que es propaga riu avall produint la incisió de la llera, fenomen conegut com a sediment starvation. Aquesta incisió és el resultat d'un desequilibri en el balanç sedimentari, ja que mentre que la capacitat de transport sòlid, que depèn del cabal líquid, de les dimensions de la llera i del seu pendent, pot tenir poques variacions, el subministrament té una reducció total o quasi total. En conques del sud de la península Ibèrica, Liquete et al. (2005) van determinar que, tot i que la construcció de preses es va iniciar l'any 1970 fins a assolir una regulació del 42\% de la superfície, el seu impacte l'any 2005 era poc perceptible a la desembocadura de rius d'entre 5 i $150 \mathrm{~km}$ de longitud. En el cas del Llobregat, on la distància entre les preses i la desembocadura és superior a $120 \mathrm{~km}$ (figura 1a i figura 3), tenint en compte la velocitat de l'ona de pertorbació de 500 m/any (Liébault et al., 2005) és força improbable que els efectes hagin arribat encara al curs baix del riu. En altres paraules, la retenció de sediment groller als grans embassaments des de l'any 1954 i 1975 no ha estat rellevant pel canvi de tendència i regressió del delta, que s'inicia mig segle abans. A llarg termini però, aquest efecte de retenció es notarà a la desembocadura.

\section{Embassaments: regulació de cabals}

Els embassaments produeixen un segon impacte en el transport de sediment riu avall a causa de l'alteració que produeixen en el règim hidrològic natural per la regulació dels cabals, més precisament degut a l'atenuació dels cabals alts i la laminació de les crescudes. Des del moment que un embassament acumula aigua, la corba de cabals classificats experimenta una reducció dels cabals alts juntament amb un increment dels baixos. Aquests canvis afecten el transport sòlid de fons per mitjà de dos trets característics del transport de sediment: (i) l'existència d'un llindar per l'inici del moviment de les partícules i, per tant, una reducció dels cabals alts implica menys dies amb cabal superior al llindar i llavors més dies sense 
transport; i (ii) la no linealitat de les equacions de transport de fons, en el sentit que una certa reducció en el cabal implica una major reducció en el transport (per exemple, si el transport de fons és proporcional al quadrat del cabal llavors la meitat de cabal implica una quarta part de transport de fons). A diferència de l'efecte de retenció de sediment, aquest impacte afecta immediatament des del moment de la construcció de l'embassament a tot el curs del riu aigua avall fins a la desembocadura ja que l'aigua triga només unes hores a fer tot el recorregut, mentre que el sediment de fons pot necessitar moltes dècades.

L'alteració del règim hidrològic s'ha analitzat mitjançant la comparació de les corbes de cabals classificats del Llobregat amb i sense embassaments. El resultat principal de la comparació de les corbes obtingudes és que, sense embassaments, el cabal és superior durant els primers 130 dies de l'any i inferior per la resta de l'any. El cabal del dia 1 de la corba de cabals classificats a l'estació d'aforament augmenta de 259 a $308 \mathrm{~m}^{3} / \mathrm{s}$, i un increment força similar i constant del 20\% també es produeix pels primers 100 dies. Tot i que la metodologia utilitzada ha permès sortejar l'absència de dades hidrològiques del Llobregat prèvies al 1954, és sensat admetre que en el cas que aquestes dades haguessin existit, la seva comparació amb la restitució del règim natural feta mitjançant el període 2002-2018 podria haver generat seriosos dubtes pel que fa a l'homogeneïtat de les dades a causa de canvis en les extraccions d'aigua, en l'escolament superficial i probablement en el règim pluviomètric.

\section{Rescloses}

En total, des de l'any 1816 fins el 1962, es van construir 91 rescloses al Llobregat i al Cardener, especialment al seu curs mig (figura 1a). L'alçada mitjana d'aquestes rescloses és de 4,2 m, amb una desviació estàndard de 2,9 m. El període de màxima construcció va ser entre els anys 1850 i 1900, quan es van construir el $62 \%$ del total. Actualment, excepte casos comptats, totes les rescloses construïdes segueixen presents al riu.

La retenció de la fracció de sediment groller a les rescloses (i), a diferència de les preses, és un efecte transitori ja que passat un cert temps des de la construcció, proporcional a la seva alçada, i sense que estiguin completament reblertes, la major part del transport de fons pot sobrepassar la resclosa per coronació i continuar riu avall (Peeters et al., 2020). La pràctica totalitat de les rescloses del Llobregat tenen més de 70 anys i el 70\% es van construir al segle xix; per tant és previsible que actualment la gran majoria ja no suposin una barrera infranquejable pel transport de fons. Tot i això, durant els anys posteriors a la seva construcció sí que van poder retenir la major part (o la totalitat) del sediment groller (especialment les rescloses més altes), produint-se un dèficit de sediment (sediment starvation) que, com en el cas de les grans preses, origina una pertorbació que es propaga riu avall.

Pel que fa a la capacitat de transport sòlid (ii), cada resclosa genera una pèrdua de desnivell lliure al riu equivalent a la seva alçada que provoca una disminució del pendent longitudinal del riu. En casos com el del Llobregat, on en trams relativament llargs hi ha successió de rescloses seguides on el rabeig d'una arriba just al peu de l'anterior, fent que el desnivell lliure del tram sigui nul, la reducció del pendent del riu és important (a les taules de la figura 3 es mostra la reducció progressiva del pendent longitudinal). La disminució del pendent provoca una reducció de la capacitat de transport sòlid que té com a conseqüència una disminució del subministrament riu avall. A diferència de l'efecte de retenció de sediment però, aquesta disminució de capacitat de transport és permanent mentre la resclosa existeixi. 
Conseqüentment, aquest impacte menys evident i que a priori podria semblar menys destacable en rius com el Llobregat és molt important. A l'apartat de discussió es realitza una anàlisi de la propagació fins al curs baix del Llobregat de la disminució de capacitat de transport sòlid del curs mig.

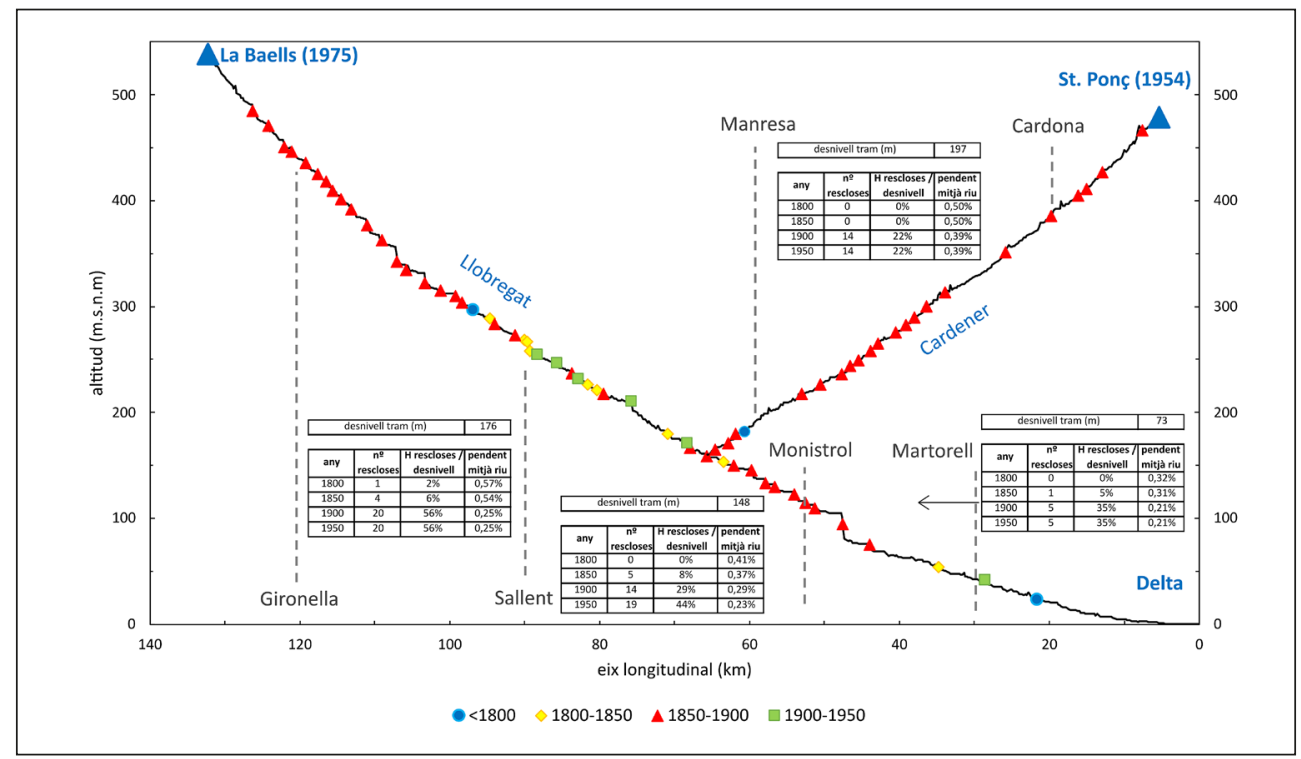

Figura 3. Perfil longitudinal del Llobregat i el Cardener on apareixen localitzades les rescloses construïdes en diferents períodes. Les taules mostren l'evolució de l'impacte de les rescloses $(H$, alçada de resclosa), mesurat en termes de pendent del riu lliure de rescloses, per diversos trams delimitats per poblacions (ubicacions a la figura 1a).

Font: elaboració pròpia utilitzant les dades d'Alayo (2017) i el model d'elevacions del terreny de 15 × 15 m de l'ICGC.

\section{Obres d'enginyeria del curs baix}

Els trams 1-3 del curs baix formen part del principal corredor viari i ferroviari venint del sud que travessa la serralada Litoral fins a la plana de Barcelona. Els anys de posada en funcionament de les infraestructures principals són: 1970 per a una autopista (que té l'efecte com un dic) que travessa la plana d'inundació pel marge esquerre; 1979 pel tall d'un meandre a la zona de Cornellà de Llobregat (figura 1b); 1998 per l'autopista homòloga (un altre dic) que travessa la plana d'inundació pel marge dret, seguida per la línia ferroviària d'alta velocitat enganxada al costat del riu d'aquesta mota; i finalment el 2004 per la nova desembocadura del riu. La figura 4a i 4b és una vista a detall d'un tram específic pròxim al municipi de Sant Vicenç dels Horts on s'observa que les autopistes han escanyat el riu i envaït i desconnectat la plana d'inundació de la llera. 


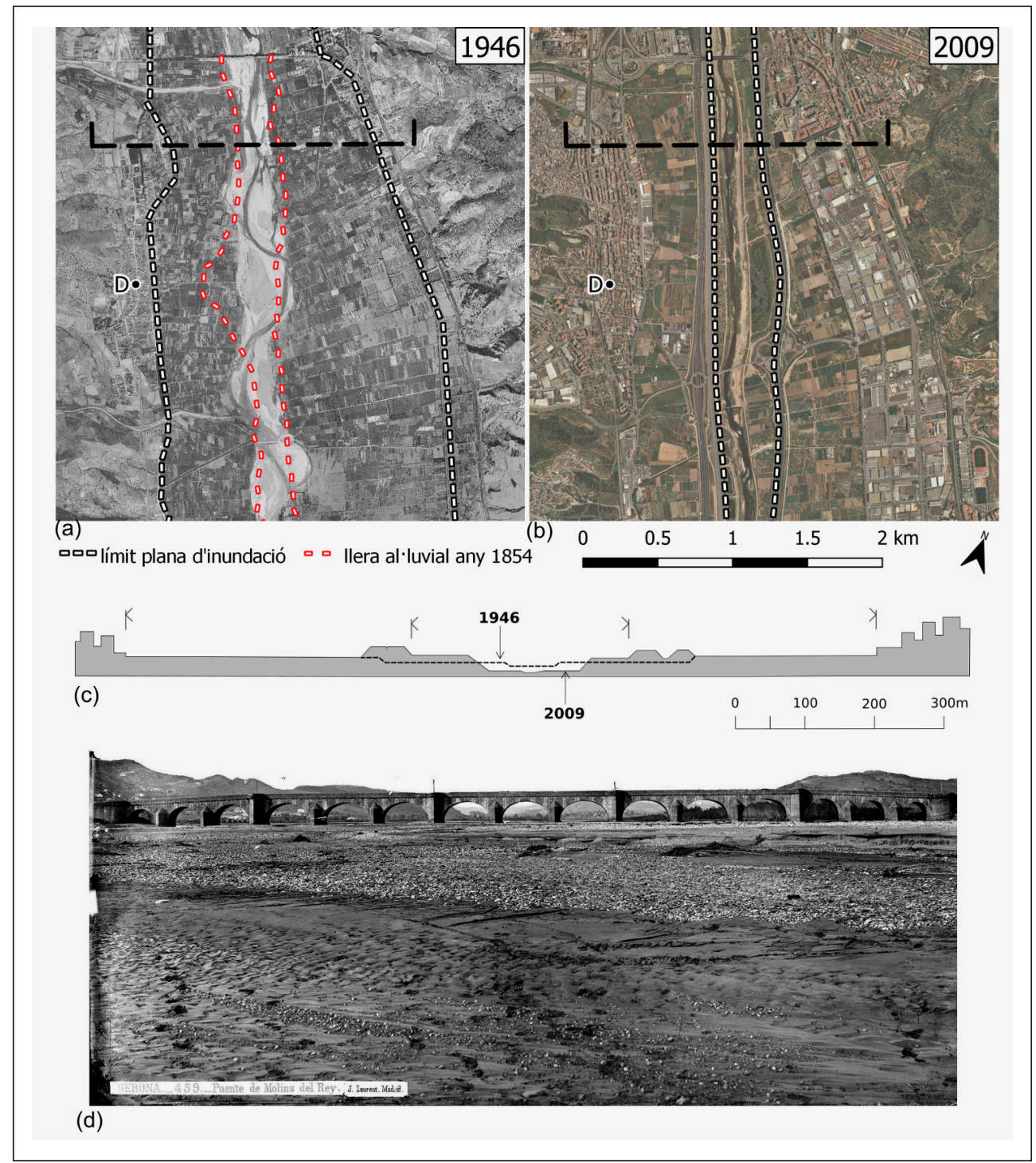

Figura 4. Imatges aèries de l'ICGC dels anys 1946 (a) i 2009 (b) del Llobregat a prop de Sant Vicenç dels Horts ( $D$, localització a la figura $1 b$. Zona d'inici del tram 3$)$, on s'observa com les infraestructures han escanyat el riu. El pont de Carles III, a la part superior de la imatge (a) i a la fotografia (d) feta l'any 1866-1867 pel fotògraf Jean Laurent. El pont va col-lapsar l'any 1971 després d'una gran crescuda que va erosionar el llit i és el límit entre els trams 2 i 3. (c) Secció transversal del tram 3 a través del tall transversal (línia discontínua) de les imatges aèries. 
Les infraestructures han provocat l'estrenyiment del riu i una reducció molt gran de la superfície al-luvial de la llera (taula 4). Cal destacar la reducció de la superfície al·luvial fins pràcticament la meitat en el període 1946-1981 (fins a una tercera part en el tram 3). La situació actual (2016) mostra l'escenari final, per ara, de la dramàtica pèrdua de superfície al·luvial de la llera.

Taula 4. Evolució de la superfície al·luvial i l'amplada mitjana de la part estrictament al·luvial de la llera del Llobregat.

\begin{tabular}{|c|c|c|c|c|c|c|}
\hline Tram & 1, vall & 2, vall & 3, vall & 4, delta & 5, delta & total \\
\hline Longitud $(\mathrm{km})$ & 8,5 & 3 & 8 & 6,5 & 4 & 30 \\
\hline \multicolumn{7}{|c|}{ Superfície al-luvial (Ha)/ amplada mitjana (m) } \\
\hline 1946 & $148 / 175$ & $54 / 180$ & $119 / 150$ & $57 / 90$ & $35 / 90$ & $413 / 138$ \\
\hline 1956 & $86 / 100$ & $33 / 110$ & $57 / 70$ & $42 / 65$ & $25 / 62$ & $243 / 81$ \\
\hline 1965 & $106 / 125$ & $47 / 157$ & $67 / 84$ & $41 / 63$ & $28 / 70$ & $289 / 96$ \\
\hline 1974 & - & $49 / 163$ & $53 / 66$ & $43 / 66$ & $30 / 75$ & $175 / 81^{\mathrm{b}}$ \\
\hline 1981 & - & $30 / 100$ & $41 / 51$ & $54 / 83$ & $30 / 75$ & $155 / 72^{\mathrm{b}}$ \\
\hline 2016 & $28 / 33$ & $18 / 60$ & $29 / 36$ & $23 / 35$ & $77 / 190^{\mathrm{a}}$ & $98 / 38^{\mathrm{c}}$ \\
\hline
\end{tabular}

${ }^{a}$ Aquest valor és degut a la nova desembocadura. ${ }^{b}$ Valors pels darrers $21,5 \mathrm{~km}$ del riu (trams 2-5). ${ }^{\circ}$ Ídem pels primers $26 \mathrm{~km}$. Font: (Prats-Puntí, 2018).

Les infraestructures de connexió de Barcelona són una de les causes que expliquen aquest canvi, però el calendari de la seva construcció suggereix que només les quatre últimes files de la taula 4, que manifesten la reducció de l'amplada al·luvial mitjana des de 96 m (1965), a 72 m (1981) i fins finalment només 38 m (2016), són atribuïbles a les infraestructures. La reducció d'amplada al·luvial s'havia iniciat amb anterioritat.

A la figura 5 presentem dues comparacions de fotografies del riu, fetes des d'exactament els mateixos punts i amb més d'un segle de diferència, que mostren la perspectiva des del pont del Diable $(a)$ i des del campanar de l'església de Sant Boi de Llobregat (b) (veure la figura 1b per ubicar-los). S'obté la mateixa conclusió d'aquest canvi dramàtic a partir dels plànols dels anys 1846 i 1854 de l'arxiu històric, ja que demostren que l'amplada al·luvial mitjana de la llera en aquella època $(272 \mathrm{~m})$ pràcticament doblava el valor d'un segle després (150 m, any 1946) i multiplica per set l'amplada actual (36 m, 2016). 


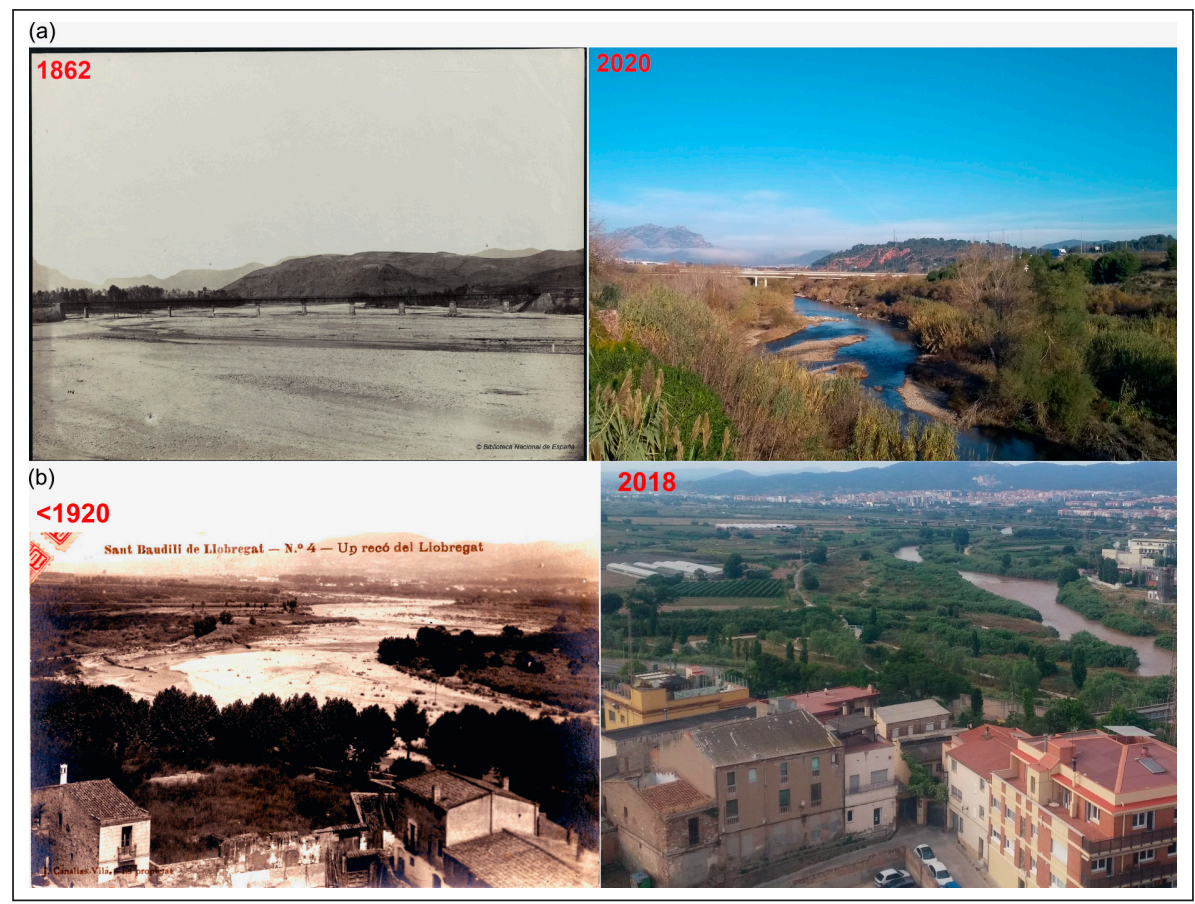

Figura 5. Fotografies del Llobregat en dos indrets del curs baix. A dalt (a) des del Pont del Diable mirant riu amunt, on destaca el pont de la línia de ferrocarril Barcelona-Vilafranca inaugurat el 1856 (a la imatge actual és un pont nou situat en el mateix emplaçament). A baix (b), des del campanar de Sant Boi de Llobregat mirant també riu amunt. Les fotografies històriques s'han obtingut de la Biblioteca Nacional de España (a) i de l'Arxiu Nacional de Catalunya (b); les actuals són fetes pels autors.

La taula 4 proporciona valors a la font de subministrament del transport de fons i, per tant, és útil com a indicador de l'evolució en el temps del subministrament de sediment al curs baix del Llobregat. A diferència de l'efecte de les preses situades a capçalera, la pertorbació d'aquesta font de subministrament és probable que pugui afectar el curs baix del Llobregat, com a mínim el tram immediatament riu avall del considerat, si es considera la velocitat de pertorbació de 500 m/any (Liébault et al., 2005). En una dècada llavors, 1946-1956 per exemple, el tram 2 rebria l'impacte de la retallada de subministrament del tram 1, i successivament pels següents trams i dècades. Una altra diferència respecte l'efecte de les preses és que en aquest cas la pertorbació no és necessàriament una incisió de la llera ja que cada tram riu avall pateix una reducció al·luvial equiparable a la del tram anterior.

\section{Evolució del transport de sediment groller}

Una primera conclusió dels resultats obtinguts és que la ràtio de la capacitat de transport amb i sense embassaments és de 0,62 de mitjana pels trams 1-4 i 0,73 pel tram 5. En altres paraules, la regulació 
de cabals provocada pels embassaments és responsable d'una reducció del 38\% de la capacitat de transport actualment (trams 1-4). Com era de preveure degut a la no linealitat de la capacitat de transport sòlid, aquesta reducció pràcticament dobla la reducció del $\approx 20 \%$ del valor de la corba de cabals classificats actual respecte a la que no té embassaments (apartat "Embassaments: regulació de cabals").

El balanç entre el subministrament i la capacitat de transport resulta en un creixement de la cota del llit si el primer supera el segon (>), i llavors el transport riu avall és només la capacitat de transport, no el subministrament. Si succeeix el contrari $(<)$, el transport és el subministrament sumant-li el material del llit (es produeix incisió), sempre i quan el llit al·luvial no s'hagi exhaurit, tendint com a màxim a la capacitat de transport. A la taula 5 , assumint que la capacitat de transport calculada en un tram es transfereix al següent riu avall en un lapse d'una dècada (justificat a l'apartat "Obres d'enginyeria del curs baix") servint-hi com a subministrament (cas $>$ ) o com a tendint a subministrament $($ cas $<$ ), es mostren les mitjanes dels valors anuals de sediment transportats pel riu Llobregat al curs baix.

Els valors de l'última columna de la taula 5 són una estimació de l'aportació de sediment (sorra) cap al mar, que és de $\approx 16 \times 10^{3} \mathrm{~m}^{3}$ /any en el període $1956-1965$ però $\approx 10 \times 10^{3} \mathrm{~m}^{3} /$ any pel de 1974 1981. Si el riu no hagués estat regulat per les preses, l'aportació de 1974-1981 hauria augmentat fins a $\approx 13 \times 10^{3} \mathrm{~m}^{3} /$ any.

Taula 5. Evolució del transport de sediment groller $\left(x 10^{3} \mathrm{~m}^{3} / \mathrm{any}\right)$ del curs baix del Llobregat. Les quantitats al costat dret dels símbols $>0<$ són les capacitats de transport del tram; les del costat esquerre són els subministraments transferits des del tram riu amunt. Les cel/les de color gris més fosc representen creixement del llit probable $(>)$ i les de gris clar incisió $(<)$. Les línies

puntejades signifiquen transferència cap al següent tram i dècada, i les fletxes signifiquen transferència a la costa. ${ }^{a}$ Calculat amb cap embassament operatiu. ${ }^{b}$ Calculat amb els 3 embassaments operatius. ${ }^{\circ}$ Aquesta xifra és deguda a la nova desembocadura. Font de les dades de capacitat de transport: (Prats-Puntí, 2018).

\begin{tabular}{|c|c|c|c|c|c|c|}
\hline Tram & 1 & 2 & 3 & 4 & 5 & cap a la costa \\
\hline $1946^{\mathrm{a}}$ & $5,6-$ & 12,9 & 9,6 , & 12,0 & 12,7 & $\rightarrow 12,7$ \\
\hline $1956^{\mathrm{a}}$ & $7,5-$ & $5,6<11,6$ & $+2,2 \geq 8.9$ & $-y, 6 \leq 14,2$ & $-12,0<16,1$ & $\rightarrow<16,1$ \\
\hline $1965^{\mathrm{a}}$ & $7, .5-$ & $7,5<16,2$ & $T 1,6 \geq 9,8$ & $--8,9 \leq 14,1$ & $\|_{14,2}<16,3$ & $\rightarrow<16,3$ \\
\hline $1974^{\mathrm{b}}$ & - & $7,5>4,6$ & $T \sigma, 2 \geq 2,3$ & $-9,8 \geq 4,9$ & $\mathbf{A}_{14,1}>10,7$ & $\rightarrow 10,7$ \\
\hline $1981^{\mathrm{b}}$ & - & 5,3 & $7,6 \geq 1,8$ & $-2,3<3,7$ & $\Rightarrow 4,9<10,5$ & $\rightarrow<10,5$ \\
\hline $2016^{\mathrm{b}}$ & 3,9 & 9,8 & $5,3<5,4$ & $\boldsymbol{A}_{1,8<7,9}$ & $3,7>0,95$ & $\rightarrow 0,95^{c}$ \\
\hline
\end{tabular}

Comparant la taula $5 \mathrm{amb}$ la taula 2 s'observa que la reducció estimada de l'aportació des dels $\approx 16 \times 10^{3} \mathrm{~m}^{3} /$ any del 1956 fins els $\approx 10 \times 10^{3} \mathrm{~m}^{3} /$ any del 1981 és un factor rellevant per l'evolució del delta ja que és del mateix ordre de magnitud però inferior que el balanç del delta entre 1946 i 1981 
$\left(-38 \times 10^{3} \mathrm{~m}^{3} /\right.$ any $)$. La variació de $\approx-6 \times 10^{3} \mathrm{~m}^{3} /$ any entre 1956 i 1981 degut a l'estrenyiment del riu per les infraestructures no és molt substancial però representa aproximadament un $16 \%$ del balanç. El paper de la regulació per les preses, que és una variació de $\approx-3,5 \times 10^{3} \mathrm{~m}^{3} /$ any, representa un $9 \%$ del balanç. Cal ressaltar que el càlcul s'ha fet utilitzant cabals mitjans i crescudes anuals, sense incloure les grans crescudes. L'evolució del delta però respon també a l'aportació de les grans crescudes del riu.

Paper de les grans crescudes

La crescuda del juny de l'any $2000 \mathrm{amb}$ una punta de $1.500 \mathrm{~m}^{3} / \mathrm{s}$ es va produir just després de la construcció del dic esquerre (segona autopista) l'any 1998. Comparant el perfil longitudinal del riu un cop finalitzades les obres amb una batimetria immediatament posterior a la crescuda s'obté un volum erosionat a la llera de $\approx 125 \times 10^{3} \mathrm{~m}^{3} /$ any als trams de la vall (1-3) (Martín-Vide et al., 2020). Tot aquest volum, com a mínim, va ser transmès cap al delta (4-5) i finalment a la costa. Comparant aquest gran volum amb els valors de les taules 5 i 2 es constata el paper dominant de les grans crescudes en el transport de sediment. Tal com explica la teoria, el llit del riu va proveir sediment a costa d'una incisió de la llera.

El resultat obtingut de volum d'aportació de sediment d'entre $10 \times 10^{3}-16 \times 10^{3} \mathrm{~m}^{3} /$ any és una subestimació molt gran en anys amb grans crescudes, les quals poden actuar com a grans entrades de sorra impulsant l'evolució del delta. És un repte saber fins a quin punt és així amb les dades escasses de què es disposa. En tot el segle xx es van produir fins a nou grans crescudes similars (i superiors) a la del 2000 (Codina, 1971), pel que un valor d'aportació "per any", molt a l'engròs, resultaria ser de $14 \times 10^{3} \mathrm{~m}^{3}$ /any. Llavors, l'aportació total mitjana, incloent les grans crescudes, doblaria el càlcul obtingut per cabals normals i crescudes anuals, i seria de $24 \times 10^{3}-30 \times 10^{3} \mathrm{~m}^{3} /$ any.

La nova desembocadura i validació del càlcul amb dades reals

L'any 2004 va entrar en funcionament la nova desembocadura del riu Llobregat desviant el curs del riu en direcció sud per tal d'ampliar el port de Barcelona (figura 1b). És un endegament amb una llera molt ampla (105 m a l'inici i $215 \mathrm{~m}$ al final) i amb un fons pràcticament pla excavat fins a una cota de -2 m (per sota el nivell del mar). La nova amplada és més del doble que la que tenia la desembocadura original (taula 4), fet que provoca que la seva capacitat de transport i, per tant, l'aportació de sediment a la costa (taula 5), disminueixi en un ordre de magnitud. Com a conseqüència, l'actual desembocadura del Llobregat, a diferència de l'original, és un estuari propens a l'acumulació de sediment.

No és sorprenent, llavors, que una batimetria feta l'any 2009 revelés una sedimentació de $700 \times 10^{3} \mathrm{~m}^{3}$ a la nova desembocadura (equivalent a un creixement de 0,5 m), que representa una mitjana de $140 \times 10^{3} \mathrm{~m}^{3}$ /any entre el 2005 i 2009. El sediment acumulat a la desembocadura no és només sorra, sinó també part de la càrrega en suspensió (sediment fi). En altres paraules, és la suma del transport de fons i part del transport en suspensió, és a dir el transport sòlid total. La comparació d'aquesta xifra de transport total amb la xifra de transport en suspensió de $\approx 90 \times 10^{3} \mathrm{~m}^{3}$ /any (Liquete et al., 2009), demostra que la component del transport de fons no és negligible.

La ràtio entre el transport sòlid de fons anual $\left(10 \times 10^{3}-16 \times 10^{3} \mathrm{~m}^{3} /\right.$ any per als anys sense grans crescudes) i el volum de sediment per any atrapat a la nova desembocadura és del $\approx 10 \%$. Aquest 
valor és molt similar a la ràtio del $9 \%$ obtinguda per tres rius mediterranis de dimensions similars al Llobregat, l'Arno, el Pescara i el Var (Syvitski \& Saito, 2007). Aquesta similitud dona confiança als càlculs d'aquest article.

\section{Discussió I CONCLUSIONS}

El transport sòlid de fons del riu Llobregat de les darreres dècades ha estat influenciat per les obres d'endegament realitzades al curs baix del riu, prou proper a la costa per tal que els canvis en aquesta zona s'hagin notat al delta. Les fonts de sediment al·luvial del llit pels trams 1-3 s'han reduït respecte els valors de l'any 1946, essent un 38\% el 1981 i només un 22\% el 2016 (taula 4). L'endegament del riu també ha provocat la reducció de la capacitat de transport sòlid de fons (taula 5), i per exemple en els trams 1-3 (any 2016) representa només un 67\% respecte la capacitat del 1946. La capacitat de transport determina el transport de sediment que aporta el riu a la costa, que disminueix dels $16 \times 10^{3} \mathrm{~m}^{3} /$ any del 1956 fins els $10 \times 10^{3} \mathrm{~m}^{3} /$ any del 1981 . Aquesta quantitat representa aproximadament el 10\% del transport sòlid total, mesurat accidentalment a la nova desembocadura problemàtica. La concordança amb la bibliografia de la ràtio del transport de fons respecte el transport total dona validesa als càlculs. Tots aquests resultats s'han obtingut considerant la situació de cabals normals i crescudes anuals ja que les grans crescudes excedeixen les quantitats anteriors amb diferència (un ordre de magnitud). A l'apartat "Paper de les grans crescudes" s'estimen per les grans crescudes uns altres $14 \times 10^{3} \mathrm{~m}^{3} /$ any d'aportació de mitjana al llarg del segle xx. Un altre actuació antròpica fins ara no mencionada que té un impacte directe en el transport sòlid d'un riu són les extraccions de material al·luvial de la llera. Pel cas del Llobregat, mitjançant les imatges aèries s'ha detectat que al curs baix la màxima activitat d'extraccions va ser entre els anys 1965 i 1981. Per proximitat a la desembocadura, aquestes extraccions haurien d'haver provocat una reducció ràpida i rellevant de l'aportació de sediment a la costa, però el seu impacte no s'ha pogut quantificar ja que no es disposa de dades dels volums extrets de la llera.

L'aportació de sediment fluvial a la costa encara no ha tingut una reducció més forta gràcies a que el llit al·luvial del riu ha proveït molt material, provinent de la seva incisió en diversos trams. A més, des de la seva posada en funcionament l'any 2004, la nova desembocadura ha dificultat més la sortida de sorra cap a la costa ja que actua com una trampa de sediment que provoca tal impacte en el transport sòlid de fons que l'aportació actual s'ha reduït en un ordre de magnitud fins aproximadament $\approx 1 \times 10^{3} \mathrm{~m}^{3} /$ any (taula 5 ). L'escenari de futur és encara d'una major retallada de sediment per les platges del delta degut al possible esgotament del llit al-luvial en els trams endegats i a la trampa de sediment de la desembocadura. Està justificada la elaboració d'un model hidràulic i morfològic de la desembocadura que es podria calibrar i validar mitjançant batimetries i mesures de transport en suspensió. Seria un model de gran utilitat per conèixer més a fons la dinàmica sedimentària d'aquest nou estuari i preveure l'evolució futura de l'aportació de sediment a la costa i de l'augment del risc d'inundació de les zones limítrofes.

S'ha justificat que la retenció de sediment a les preses de la conca del Llobregat té menor impacte en el transport de sediment groller a la costa que l'impacte que generen per la regulació dels cabals riu 
avall, que suposa una reducció del 38\% en la capacitat de transport sòlid al curs baix del riu. Tot i això, alguns efectes de la captura de sediment a les preses podrien aparèixer a llarg termini.

Malgrat tot però, la influència dels endegaments “moderns" del riu en l'evolució del delta és sobrepassada per una tendència a llarg termini més important del delta del Llobregat que, com s'explica a continuació, sembla irreversible. De fet, la contribució dels endegaments en el retrocés produït durant el període d'anàlisi 1946-1981 s'ha estimat del 16\%. Les noves dades de l'evolució de la costa presentades demostren que l'època de màxima expansió cap al mar del delta a la desembocadura va tenir lloc durant la darrera dècada del segle XIx. La qüestió a resoldre és per què el delta el segle xix estava avançant, almenys des de l'any 1859, però retrocedint de forma continuada i accelerada durant el segle xx. A continuació s'analitzen possibles causes que expliquin el canvi de tendència produit a tombant de segle.

Estudis realitzats en rius del Sud-est de França (Liébault \& Piégay, 2002) suggereixen que una política de reforestació dels darrers 150 anys aplicada a les conques podria haver estat influent en l'estrenyiment produït a les lleres dels rius i indirectament també en la regressió de deltes. Aquesta hipòtesi pel cas del Llobregat topa amb el fet que la reducció de fonts de sediment (disminució del terreny agrícola i augment del forestal) a partir de les dades disponibles sembla molt modesta (taula 3), i encara seria menor la influència segons recerques recents que demostren la poca influència de la desforestació en la mida dels deltes ja que el sediment fi contribueix poc en la seva progressió (Ibáñez et al., 2019).

Una segona causa possible és un règim hidrològic particular durant el segle xıx. Gràcies a la recerca bibliogràfica s'ha pogut determinar que el període 1830-1870 va estar marcat per una freqüència elevada de grans crescudes al riu Llobregat i d'altres rius mediterranis de Catalunya (Barriendos et al., 2019; Llasat et al., 2005). Les crescudes més greus van tenir lloc els anys 1837, 1842, 1853 i 1866 (Barriendos \& Rodrigo, 2006). El segle xx ha estat menys actiu: 6 episodis catastròfics el segle xIx respecte només 1 el segle xx (Llasat et al., 2005). Es pot assumir que aquestes grans crescudes van produir un avançament important del delta.

La tercera causa és el gran nombre de rescloses que es van construir des de la segona meitat del segle xix. El gràfic de la figura 6 mostra l'evolució temporal de l'alçada acumulada de les recloses de la conca del Llobregat. A mesura que es van anar construint les rescloses el desnivell lliure del perfil longitudinal del riu pel flux d'aigua i sediment es va reduir progressivament. Com que la capacitat de transport sòlid de fons és una funció d'aquest desnivell lliure, llavors aquest gràfic també serveix com a indicador de la reducció de la capacitat de transport sòlid. L'efecte endarrerit de les rescloses més llunyanes i l'efecte ràpid de les més pròximes, en el temps transcorregut des de la seva construcció fins a arribar el seu impacte al curs baix del riu, es té en compte amb tres possibles velocitats d'ona de pertorbació: 500 m/any (Liébault et al., 2005), i dues velocitats majors de $1 \mathrm{~km} / \mathrm{any}$ i $2 \mathrm{~km} / \mathrm{any}$ per representar una possible arribada més ràpida dels efectes. Les tres línies resultants expressen ritmes de descens diferents del subministrament de sediment al curs baix del Llobregat.

Hi ha dos aspectes importants de la figura 6. El primer, que l'anomalia hidrològica del període 1830-1870 troba el riu Llobregat abans de l'apogeu de construcció de rescloses. Per tant, les crescudes extraordinàries d'aquest període haurien d'haver transportat grans quantitats de sediment fins al curs baix del Llobregat. I el segon, que l'efecte in crescendo de la construcció de rescloses en l'aportació de 
sediment cap al curs baix s'estén al llarg dels segles xix (finals) i xx. A més, el fet que el canvi de tendència del delta coincideixi temporalment amb els anys de retallada més dràstica del subministrament pel cas d'una velocitat de pertorbació de $2 \mathrm{~km} /$ any (o bé l'inici de la retallada per la velocitat de 0,5 km/ any) podria explicar la relació causa-efecte que les rescloses poden haver tingut en el delta.

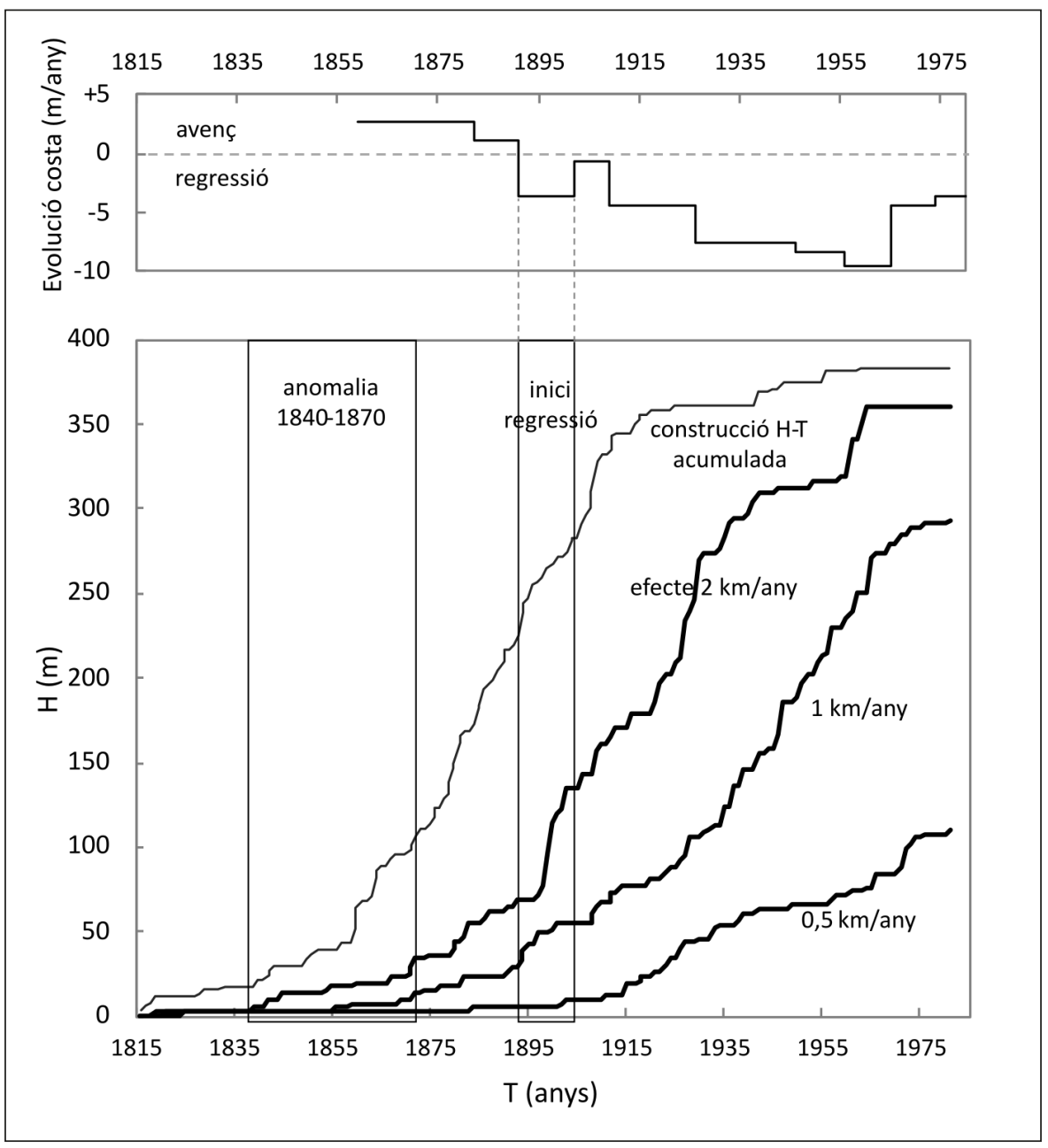

Figura 6. Alçada acumulada $(\mathrm{H})$ versus l'any de construcció de les rescloses del curs mig del riu (dades de Alayo, 2017) i el seu efecte al curs baix del Llobregat, segons tres velocitats de pertorbació diferents. El gràfic superior mostra la taxa anual d'evolució de la línia de costa del delta a la desembocadura (dades de la taula 1 pel període 1859-1956, mapa de la figura 2a pel de 19561981). La comparació d'ambdós evidencia una possible relació causa-efecte. 
En l'escenari d'un Llobregat a mitjans del segle xix lliure de rescloses al curs mig i més actiu a causa de les grans crescudes, l'amplada de la llera al-luvial al curs baix del riu era molt superior que l'actual tal i com s'intueix en les fotografies històriques del riu (figures 4d, 5a i 5b) i com demostren els dos plànols del curs baix del Llobregat datats els anys 1846 i 1854, just de ple en els anys de l'anomalia hidrològica. El clímax de l'aportació de sediment cap al delta es va produir a mitjans del segle xix. La reducció progressiva del transport de sediment des de llavors a causa de la disminució de la freqüència de grans crescudes, però sobretot de les obres d'enginyeria fetes a la llera del riu, s'ha manifestat en una regressió molt important de la costa fruit del domini de l'acció erosiva de l'onatge respecte el riu en el balanç sedimentari de la costa. Actuacions d'enretirada de rescloses, d'eixamplament de la llera en trams endegats on sigui possible, i de millora de la nova desembocadura, permetrien revertir els impactes negatius de les obres realitzades i aconseguir que a mig i llarg termini torni a augmentar l'aportació de sorra del riu a les platges del delta del Llobregat.

\section{Agraïments}

Els autors volem deixar constància del nostre agraïment a Víctor Ténez, Vicenç Gràcia, Javier Martín Vide, Carles Ibáñez, l'Arxiu Nacional de Catalunya (ANC) i a l'Arxiu Històric de la Ciutat de Barcelona. El tercer autor és Professor Serra Húnter a l'UPC.

\section{ReferènCIES}

Alayo, J. C. (2017). Aigua i energia. L'aprofitament hidroelèctric dels rius catalans. Pagès editors.

Barriendos, M., Gil-Guirado, S., Pino, D., Tuset, J., Pérez-Morales, A., Alberola, A., Costa, J., Balasch, J. C., Castelltort, X., Mazón, J., \& Ruiz-Bellet, J. L. (2019). Climatic and social factors behind the Spanish Mediterranean flood event chronologies from documentary sources (14th-20th centuries). Global and Planetary Change, 182, 1-16. https://doi.org/10.1016/j.gloplacha.2019.102997

Barriendos, M. \& Rodrigo, F. S. (2006). Study of historical flood events on Spanish rivers using documentary data. Hydrological Sciences Journal, 51(5), 765-783. https://doi.org/10.1623/hysj.51.5.765

Bridge, J. (2003). Rivers and Floodplains. Forms, Processes and Sedimentary Record. Blackwell Publishing Ltd., 487 pp.

CIIRC. (2010). Estat de la zona costanera a Catalunya. Departament de Política Territorial i Obres Públiques, Generalitat de Catalunya.

Codina, J. (1971). Inundacions al Delta del Llobregat. Col. Episodis de la Història, nos. 147-148. Barcelona: R. Dalmau.

Cui, Y. \& Parker, G. (1998). The arrested gravel front: Stable gravel-sand transitions in rivers Part 2: General numerical solution. Journal of Hydraulic Research, 36(2), 159-182. https://doi. org/10.1080/00221689809498631

Einstein, H. A. (1964). Sedimentation, Part II: River Sedimentation. En Chow, V. T. Handbook of Applied Hydrology. McGraw-Hill. 
Gràcia, V. \& Calafat, A. (2019). El hemidelta Sur del Llobregat: un sistema natural controlado por la acción humana. En X Jornadas de Geomorfología Litoral: libro de ponencias (pp. 265-269), Castelldefels, 4-6 septiembre 2019, Institut de Ciències del Mar.

Ibáñez, C., Alcaraz, C., Caiola, N., Prado, P., Trobajo, R., Benito, X., Day, J. W., Reyes, E., \& Syvitski, J. P. M. (2019). Basin-scale land use impacts on world deltas: Human vs natural forcings. Global and Planetary Change, 173, 24-32. https://doi.org/10.1016/j.gloplacha.2018.12.003

Ibisate, A., Díaz, E., Ollero, A., Acín, V., \& Granado, D. (2013). Channel response to multiple damming in a meandering river, middle and lower Aragón River (Spain). Hydrobiologia, 712(1), 5-23. https://doi.org/10.1007/s10750-013-1490-0

Liébault, F., Gomez, B., Page, M., Marden, M., Peacock, D., Richard, D., \& Trotter, C. M. (2005). Land-use change, sediment production and channel response in upland regions. River Research and Applications, 21(7), 739-756. https://doi.org/10.1002/rra.880

Liébault, F. \& Piégay, H. (2002). Causes of 20th century channel narrowing in mountain and piedmont rivers of Southeastern France. Earth Surface Processes and Landforms, 27(4), 425-444. https://doi. org/10.1002/esp.328

Liquete, C., Arnau, P., Canals, M., \& Colas, S. (2005). Mediterranean river systems of Andalusia, southern Spain, and associated deltas: A source to sink approach. Marine Geology, 222-223(1-4), 471-495. https://doi.org/10.1016/j.margeo.2005.06.033

Liquete, C., Canals, M., Ludwig, W., \& Arnau, P. (2009). Sediment discharge of the rivers of Catalonia, NE Spain, and the influence of human impacts. Journal of Hydrology, 366(1-4), 76-88. https://doi. org/10.1016/j.jhydrol.2008.12.013

Llasat, M. C., Barriendos, M., Barrera, A., \& Rigo, T. (2005). Floods in Catalonia (NE Spain) since the 14th century. Climatological and meteorological aspects from historical documentary sources and old instrumental records. Journal of Hydrology, 313(1-2), 32-47. https://doi.org/10.1016/j. jhydrol.2005.02.004

Marcos, O. (1995). Canvis recents a la línia de costa del delta del Llobregat. En Treballs de la Societat Catalana de Geografia, 39, 45-72. https://raco.cat/index.php/TreballsSCGeografia/article/ view/184531

Marquès, M. A. (1984). Les formacions quaternàries del delta del Llobregat. Institut d'Estudis Catalans, $208 \mathrm{pp}$.

Martín-Vide, J. P. \& Andreatta, A. (2009). Channel degradation and slope adjustment in steep streams controlled through bed sills. Earth Surface Processes and Landforms, 34(1), 38-47. https:// doi.org/10.1002/esp.1687

Martín-Vide, J. P., Prats-Puntí, A., \& Ferrer-Boix, C. (2020). What controls the coarse sediment yield to a Mediterranean delta? The case of the Llobregat River (NE Iberian Peninsula). Natural Hazards and Earth System Sciences, 20(12), 3315-3331. https://doi.org/10.5194/NHESS-20-3315-2020

Orton, G. J. \& Reading, H. G. (1993). Variability of deltaic processes in terms of sediment supply, with particular emphasis on grain size. Sedimentology, 40(3), 475-512. https://doi. org/10.1111/j.1365-3091.1993.tb01347.x 
Paladella, F. \& Faura-Sans, M. (1935). Experiències sobre l'avançament de delta del Llobregat. Arxius de l'Escola Superior d'Agricultura, 1, 150-157. https:/upcommons.upc.edu/handle/2099/11137

Peeters, A., Houbrechts, G., Hallot, E., Van Campenhout, J., Gob, F., \& Petit, F. (2020). Can coarse bedload pass through weirs? Geomorphology, 359, 107-131. https://doi.org/10.1016/j. geomorph.2020.107131

Prats-Puntí, A. (2018). Estudi morfodinàmic de l'evolució històrica del tram baix del riu Llobregat [UPC]. https://upcommons.upc.edu/handle/2117/131247

Sánchez-Arcilla, A., Jiménez, J. A., Valdemoro, H. I., \& Gracia, V. (2008). Implications of climatic change on Spanish Mediterranean low-lying coasts: The Ebro delta case. Journal of Coastal Research, 24(2), 306-316. https://doi.org/10.2112/07A-0005.1

Syvitski, J. P. M. \& Saito, Y. (2007). Morphodynamics of deltas under the influence of humans. Global and Planetary Change, 57(3-4), 261-282. https://doi.org/10.1016/j.gloplacha.2006.12.001

Wilkinson, B. H. \& McElroy, B. J. (2007). The impact of humans on continental erosion and sedimentation. Bulletin of the Geological Society of America, 119(1-2), 140-156. https://doi.org/10.1130/ B25899.1

Wong, M. \& Parker, G. (2006). Reanalysis and Correction of Bed-Load Relation of Meyer-Peter and Müller Using Their Own Database. Journal of Hydraulic Engineering, 132(11), 1159-1168. https:// doi.org/10.1061/(asce)0733-9429(2006)132:11(1159)

Cómo citar este artículo:

Prats Puntí, A., Martín Vide, J. P., \& Ferrer Boix, C. (2021). Efectes de les obres d'enginyeria al riu Llobregat i regressió del seu delta d'ençà del segle xix. Cuadernos de Geografía, 107, 123-148.

https://doi.org/10.7203/CGUV.107.21307

\section{(C) $(1) \Theta$}

Este obra está bajo una licencia de Creative Commons Reconocimiento-NoComercial-SinObraDerivada 4.0 Internacional. 